\title{
Haemorrhage through the ampulla of Vater
}

\author{
W.J. Ribbans, R.E. Pounder and I. Lindsay \\ Academic Department of Medicine and Department of Morbid Anatomy, Royal Free Hospital School of Medicine, \\ Rowland Hill Street, Hampstead, London NW3 2PF, UK.
}

\begin{abstract}
Summary: A patient with chronic pancreatitis presented with a series of massive upper gastrointestinal haemorrhages due to bleeding into the pancreatic duct. This report emphasizes the value of intensive investigation before surgery, since it may be impossible to identify the site of bleeding at laparotomy.
\end{abstract}

\section{Case report}

A 70 year old retired dock porter presented to his local hospital with a haematemesis. He had always been healthy apart from a 1 month episode of epigastric pain $3 \mathrm{y}$ earlier. He gave no history of either drug or alcohol abuse.

The patient's presenting haemoglobin was $4.5 \mathrm{~g} / \mathrm{dl}$. A laparotomy was performed at that hospital for a presumed bleeding peptic ulcer, but a gastrotomy revealed only gastritis. Over the next 10 weeks the patient had four further episodes of haematemesis and melaena, and was managed conservatively with multiple blood transfusions, cimetidine and carbenoxolone. Upper gastrointestinal endoscopy on three occasions failed to reveal the source of haemorrhage.

Four months after the first haematemesis, the patient was referred to the Royal Free Hospital. On examination the spleen tip could be palpated. Electivc endoscopy revealed possible gastric varices and a prominent ampulla of Vater. The only laboratory abnormality was a raised gamma glutamyl transpeptidase (142 U/l, normal 7-30 U/l).

Two days after admission the patient had epigastric pain for several hours, followed by a 2 litre haematemesis. Emergency endoscopy again failed to identify the source of haemorrhage, but fresh blood was noticed near the ampulla of Vater. Emergency selective mesenteric arteriography revealed a blocked dorsal pancreatic artery (Figure 1) and an absent splenic vein with gastric varices (Figure 2). Ultrasound revealed a $2 \mathrm{~cm}$ semi-cystic mass in the pancreas, infero-posterior to the splenic vein and anterior to the superior mesenteric artery (Figure 3). Endoscopic retrograde cholangio-pancreatography (ERCP) revealed a distorted pancreatic duct, apparently due to

Correspondence: R.E. Pounder, M.A., M.D., F.R.C.P., Academic Department of Medicine, Royal Free Hospital, London NW3 2QG, UK

Accepted: 6 March 1984

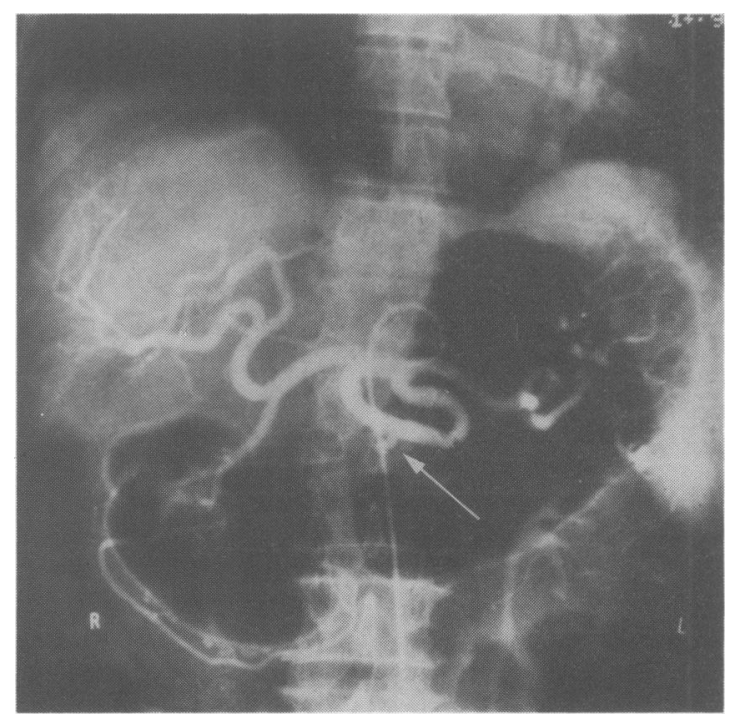

Figure 1 Elective mesenteric arteriogram. Blocked dorsal pancreatic artery (arrow).

chronic pancreatitis, with an $8 \times 12 \mathrm{~mm}$ cavity containing a single filling defect (Figure 4). As the ERCP cannula was withdrawn clots of blood came from the ampulla of Vater.

At laparotomy, there appeared to be a mass in the body of the pancreas, macroscopically like a carcinoma but without evidence of metastasis. The distal pancreas, to the level of the superior mesenteric artery, and the spleen were resected to control the recurrent haemorrhage. The patient made an uneventful recovery and has not rebled during $2 \mathrm{y}$ of follow-up.

The pancreas showed a mottled cut-surface in which the normal lobular architecture was replaced by areas of paler, ill-defined haemorrhage. Histologically there was no evidence of malignancy. The appearance was that of chronic pancreatitis with survival of islets in an 


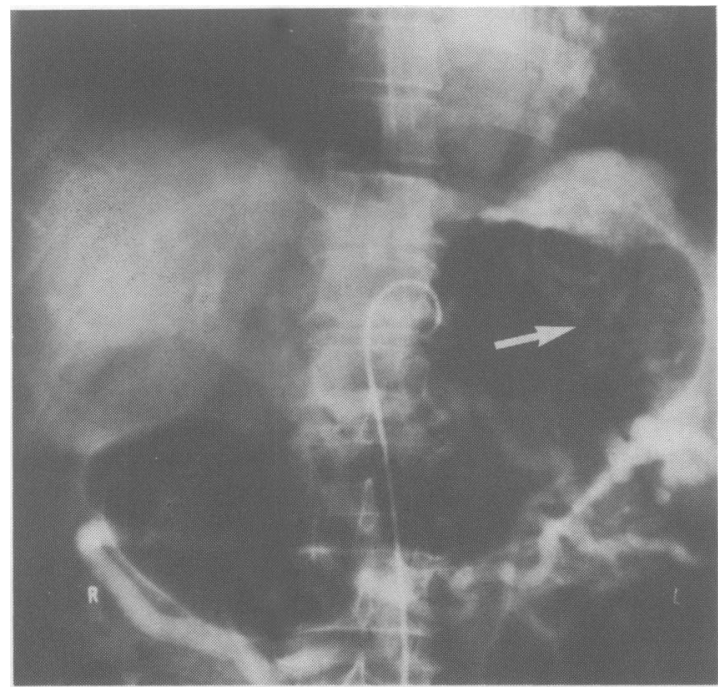

Figure 2 Venous phase of the arteriogram. Numerous gastric varices (arrow) and an absent splenic vein.

otherwise fibrotic gland. The vessels showed signs of previous damage: organizing and recanalized thrombi, and extravasated iron pigment with some recent thrombus. Neither a single bleeding point nor cystic dilatation was found in the specimen.

\section{Discussion}

The pancreas is an unusual source of upper gastrointestinal haemorrhage. Patients with chronic pancreatitis bleed from other parts of the upper gastroin-

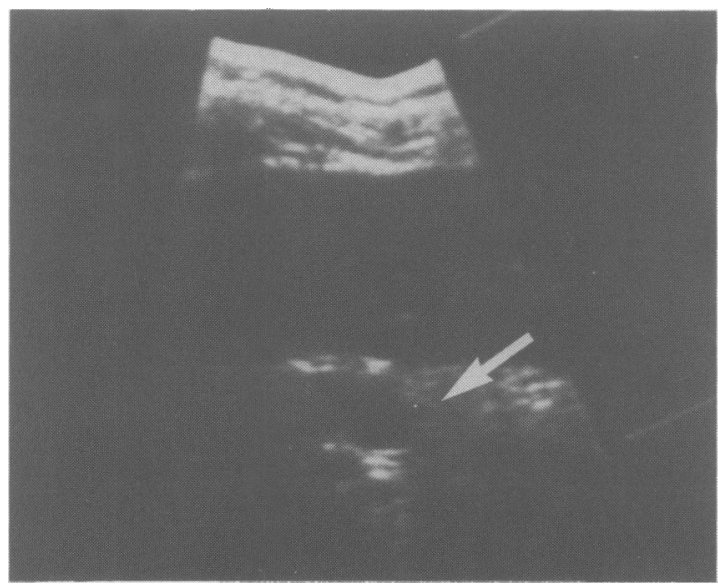

Figure 3 Ultrasound. Semi-cystic mass in the pancreas (arrow).

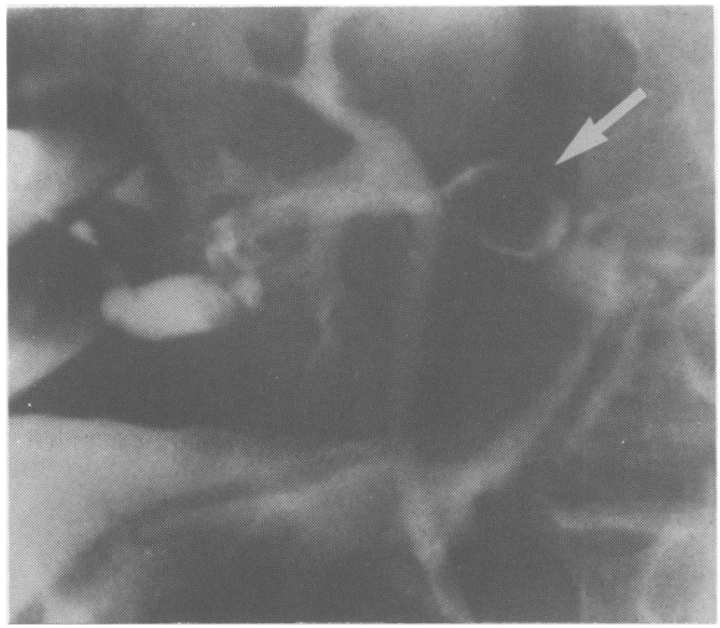

Figure 4 Endoscopic retrograde pancreatogram. A distorted pancreatic duct containing a single filling defect (arrow). A pyelogram is superimposed on the pancreatic duct.

testinal tract: gastritis, peptic ulcer and portal hypertension are all common, especially in alcoholics. Even in a series of patients with haemobilia, only 7 had haemorrhage originating from the pancreas (Sands blom, 1972). Up to 1976, there were reports of only 39 patients who had haemorrhaged through the ampullat of Vater - and none had been assessed endoscopically? (Van Kemmel et al., 1976).

Seventy-eight percent of patients in one series who bled from the pancreas had chronic pancreatitis complicated by pseudocyst formation, the remainder bled from pseudoaneurysms due to pressure necrosis and enzyme digestion by expanding pseudocysts, which have no epithelial lining (Frayssinet et al., 1978). The splenic artery was most commonly affected, but the gastro-duodenal, pancreatico-duodenal, gastric and hepatic arteries, as well as the aorta, have also been involved (Britnall et al., 1974). The pseudoaneurysm may erode and bleed into the stomach, duodenum, transverse colon, common bile duct, or peritoneal cavity. Haemorrhage may occur spontaneously or after surgical drainage of the pseudocyst. Least commonly haemorrhage may occur through the ampulla of Vater (Britnall et al., 1974; Rosch et al., 1976; Pasquali \& Corsi, 1973; Kaplan et al., 1980).

Bleeding from the pancreas is not always associated with pseudocyst formation; it may occur during acute haemorrhagic pancreatitis, be associated with spontaneous aneurysms of the splenic artery, or be due to pancreatic neoplasia which may cause either local bleeding or local portal hypertension, due to splenic vein thrombosis. 
The patient described in the present report is unusual as he did not give a history of chronic pancreatitis apart from a 1 month episode of undiagnosed abdominal pain. The dorsal pancreatic artery as well as the splenic vein were both occluded. As no malignant tissue was identified, and the patient remains healthy, it is assumed that the vascular disturbances were due to chronic pancreatitis with bleeding from an unknown vessel into the pancreatic duct probably due to distal splenic venous hypertension. Although cystic dilatation of the pancreatic duct was seen on both ultrasound and ERCP, there was no classical pancreatic pseudocyst.

Angiography, ultrasound, endoscopy and ERCP (Britnall et al., 1974; Rosch et al., 1976; Kaplan et al., 1980) have all been used to identify bleeding from the pancreas. In this patient it was only after the use of all

\section{References}

BRITNALL, B.B., LAIDLAW, W.W. \& PAPP, J.P. (1974). Haemobilia: pancreatic pseudocyst haemorrhage demonstrated by endoscopy and arteriography. Digestive Diseases and Sciences, 19, 186.

FRAYSSINET, R., SAHEL, J. \& SARLES, E. (1978). Les wirsungorragies. Gastroenterologique Clinique et Biologique, 2, 993.

KAPLAN, R.P., KAPLAN, L., PARISH, J. \& TREIMAN, R. (1980). Hemobilia - endoscopic diagnosis and association with pancreatitis. Digestive Diseases and Sciences, 23, 140. PASQUALI, E. \& CORSI, A. (1973). Haemorrhage in pan- four techniques that an exact pre-operative diagnosis was achieved.

Although bleeding pancreatic vessels have been embolized, this patient already had an obliterated pancreatic artery. The distal pancreatectomy and splenectomy may have cured him either by resection of an underlying bleeding vessel or by elimination of the distal splenic venous hypertension.

\section{Acknowledgements}

The authors thank Professor K.E.F. Hobbs who performed the distal pancreatectomy, Dr R. Dick who performed the arteriogram, Dr. L.A. Berger who performed the ultrasound and Dr J.M. Rhodes who performed the endoscopic pancreatography.

creatic inflammatory pseudocyst. Chirurgie Gastroenterologique, 7, 310.

ROSCH, W., SCHAFFNER, O., FRUHMORGEN, P. \& KOCH, H. (1976). Massive gastrointestinal haemorrhage into the pancreatic duct - diagnosed by duodenoscopy and E.R.C.P. Endoscopy, 8, 93.

SANDBLOM, P. (1972). In Haemobilia (biliary tract haemorrhage), p. 6. C.C. Thomas: Springfield.

VAN KEMMEL, M., PARIS, J.C., L'HERMINE, C. \& HOUCKE, M. (1976). Les wirsungorragies. Médecene et Chirurgie Digestives, 5, 53. 